\title{
Meteorological atmospheric boundary layer measurements and ECMWF analyses during summer at Dome C, Antarctica
}

\author{
Christophe Genthon, ${ }^{1}$ Michael S. Town, ${ }^{1}$ Delphine Six, ${ }^{1}$ Vincent Favier, ${ }^{1}$ \\ Stefania Argentini, ${ }^{2}$ and Andrea Pellegrini ${ }^{3}$ \\ Received 26 June 2009; revised 7 September 2009; accepted 2 October 2009; published 5 March 2010.
}

[1] Six levels of meteorological sensors have been deployed along a $45 \mathrm{~m}$ tower at the French-Italian Concordia station, Dome C, Antarctic. We present measurements of vertical profiles, the diurnal cycle, and interdiurnal variability of temperature, humidity, and wind speed and direction for 3 weeks during the southern summer of 2008. These measurements are compared to 6-hourly European Center for Medium-Range Forecasts (ECMWF) analyses and daily radiosoundings. The ECMWF analyses show a $3-4^{\circ} \mathrm{C}$ warm bias relative to the tower observations. They reproduce the diurnal cycle of temperature with slightly weaker amplitude and weaker vertical gradients. The amplitude of the diurnal cycle of relative humidity is overestimated by ECMWF because the amplitude of the absolute humidity diurnal cycle is too small. The nighttime surface-based wind shear and Ekman spiral is also not reproduced in the ECMWF analyses. Radiosonde temperatures are biased low relative to the tower observations in the lowest $30 \mathrm{~m}$ but approach agreement at the top of the tower. Prior to bias correction for age-related contamination, radiosonde relative humidities are biased low relative to the tower observations in the lowest $10 \mathrm{~m}$ but agree with tower observations above this height. After correction for the age-related bias, the radiosonde relative humidity agrees with tower observations below $10 \mathrm{~m}$ but is biased high above this height. Tower temperature observations may also be biased by solar heating, despite radiation shielding and natural ventilation.

Citation: Genthon, C., M. S. Town, D. Six, V. Favier, S. Argentini, and A. Pellegrini (2010), Meteorological atmospheric boundary layer measurements and ECMWF analyses during summer at Dome C, Antarctica, J. Geophys. Res., 115, D05104, doi:10.1029/2009JD012741.

\section{Introduction}

[2] Antarctica is one of the coldest, driest places on Earth. The Antarctic plateau, in particular, experiences some of the strongest surface-based temperature inversions ever observed [Schwerdtfeger, 1970, 1984; Hudson and Brandt, 2005]. The atmospheric boundary layer (ABL) of the Antarctic plateau has been studied for many purposes ranging from purely climatological [e.g., Kuhn et al., 1977; Argentini et al., 2005; van As et al., 2005; Hudson and Brandt, 2005; van As and van den Broeke, 2006] to astronomical [e.g., Travouillon et al., 2003; Aristidi et al., 2005]. The Antarctic plateau itself can also be a natural laboratory and test bed for understanding extreme atmospheric processes [Lettau and Schwerdtfeger, 1971]. Model, meteorological analysis, and reanalysis evaluations [Genthon

\footnotetext{
${ }^{1}$ Laboratoire de Glaciologie et Géophysique de l'Environnement, UMR 5183, Saint Martin d'Hères, France.

${ }^{2}$ Istituto di Scienze dell'Atmosfera e del Clima, CNR, Rome, Italy.

${ }^{3}$ Programma Nazionale Ricerche in Antartide, ENEA, Rome, Italy.

Copyright 2010 by the American Geophysical Union. 0148-0227/10/2009JD012741\$09.00
}

and Braun, 1995; King and Connolley, 1997; Cullather et al., 1997; Briegleb and Bromwich, 1998; Hines et al., 1999; Bailey and Lynch, 2000; Hines et al., 2004], as well as focused studies of parameterizations of the surface atmospheric boundary layer (ABL) [e.g., Dalrymple et al., 1966; Kuhn et al., 1977; King, 1990; King and Anderson, 1994; Cassano et al., 2001; Town and Walden, 2009], have been performed using meteorological and climatic data from the Antarctic plateau.

[3] This body of literature indicates that the main challenges for models, analyses, and reanalyses over Antarctica are accurate parameterizations of clouds and the stable boundary layer. Whereas evaluations of mesoscale and general circulation models ideally employ the full suite of observations taken over the Antarctic plateau, evaluations of analyses and reanalyses over the Antarctic plateau are often limited to near-surface data because much of the available upper air data has been assimilated into their final products. Over the Antarctic plateau, there are few in situ, nearsurface measurements other than the standard meteorological levels, 2 and $10 \mathrm{~m}$. Exceptions include measurements currently taken at the South Pole at $22 \mathrm{~m}$ by the National Oceanic and Atmospheric Administration, and a few other 


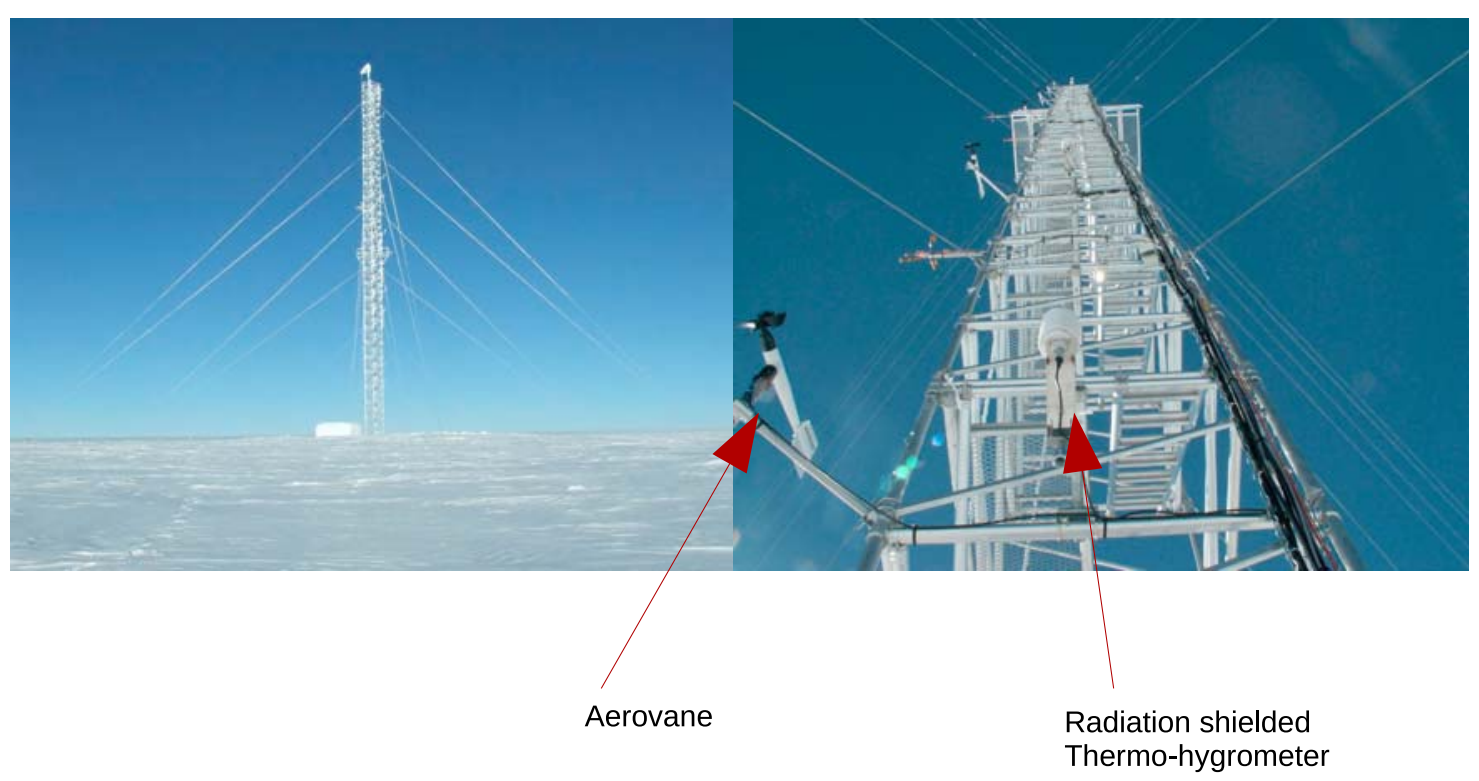

Figure 1. (left) The $45 \mathrm{~m}$ instrumented tower at Dome C, and (right) first level of instruments at $4.6 \mathrm{~m}$ above surface.

field projects of limited duration [e.g., Dalrymple et al., 1966; Kuhn et al., 1977; Hudson and Brandt, 2005].

[4] Radiosounding data exist for the Antarctic plateau since the International Geophysical Year in 1957-1958 [e.g., Schwerdtfeger, 1970, 1984; Turner et al., 2006; Walden et al., 2005; Aristidi et al., 2005; Rowe et al., 2008]. However, while high temporal resolution case studies of the ABL exist [e.g., Aristidi et al., 2005; Hudson and Brandt, 2005], the available data are of insufficient length to accurately characterize the climatological diurnal cycle of the ABL.

[5] Before use, whether for operational or research purposes, historical radiosonde profiles often require corrections for temporal lags [e.g., Mahesh et al., 1997; Hudson et al., 2004; Miloshevich et al., 2004] and biases due to solar radiation and contamination [Wang et al., 2002; Miloshevich et al., 2004; Rowe et al., 2008; Miloshevich et al., 2009]. Near-surface radiosonde wind reports are inaccurate because the swinging sensors often stabilize only a few tens of meters above the surface. It is not sufficient to simply interpolate between ground-based wind measurements and radiosonde winds from higher in the atmosphere because the stable $\mathrm{ABL}$ over the Antarctic plateau is a region of strong wind shear.

[6] To better characterize the near-surface atmosphere over the Antarctic plateau for meteorological and astronomical applications, the permanent French-Italian station, Concordia (Dome C, Antarctica, $74.1^{\circ} \mathrm{S}, 123.3^{\circ} \mathrm{E}, 3233 \mathrm{~m}$ a.s.l.), has been equipped with a diverse suite of meteorological instrumentation. A surface-based acoustic remote sensor (SODAR, SOund Detection And Ranging) was installed to monitor the thermal structure and dynamics of the summertime ABL [Georgiadis et al., 2002; Argentini et al., 2005; King et al., 2006]. However, much of the summer diurnal variability on the Antarctic plateau takes place close to the surface [Hudson and Brandt, 2005; Aristidi et al., 2005; van As and van den Broeke, 2006], and the high temporal resolution SODAR measurements did not have sufficient vertical resolution to sample the lower ABL. To complement this data set, six levels of standard meteorological sensors were deployed along a $45 \mathrm{~m}$ tower; they have been operational since 16 January 2008. Using this data set, we describe the behavior of near-surface temperature, humidity, and wind of the Antarctic plateau summertime ABL. We further compare these new observations to near-surface atmospheric profiles from routine radiosonde launches, and evaluate summertime operational European Center for Medium Range Forecasts (ECMWF) analyses over Dome C.

\section{Geographical Setting, Instruments, and Data}

[7] Concordia Station is a permanent station located at Dome C, Antarctica $\left(74.1^{\circ} \mathrm{S}, 123.3^{\circ} \mathrm{E}, 3233 \mathrm{~m}\right.$ a.s.l.), on the East Antarctic plateau. It is jointly operated by the French (Institut Polaire Français Paul-Émile Victor, IPEV) and Italian (Programma Nazionale Ricerche in Antartide, PNRA) polar institutes. Dome $\mathrm{C}$ is a regional topographic maximum on the plateau; local slopes do not exceed $1 \%$. The climate consists of a synoptic coastal influence that brings relatively warm, cloudy, and windy conditions, and gravity driven flow that occurs under cold, clear, calm conditions. Aristidi et al. [2005] report an annual mean $3 \mathrm{~m}$ wind speed of approximately $3 \mathrm{~m} \mathrm{~s}^{-1}$. Low wind speeds combined with frequent stable boundary layers and small surface roughness result in low atmospheric turbulence most of the time at Dome C, although weak convection has been observed during summer [Argentini et al., 2005].

\subsection{Tower Observations}

[8] Figure 1 shows the observational setup. The meteorological suite is deployed along a $45 \mathrm{~m}$ tower located about $700 \mathrm{~m}$ from the station. The tower has been situated to avoid significant influence from Concordia station, the main local orographic feature, under all flow regimes. Figure 2 is a schematic of the station. Under anticyclonic conditions, 




Figure 2. Schematic of Concordia Station. Prevailing winds under anticyclonic flow (i.e., inversion wind) come from the south-southwest direction (parallel to the skiway, indicated by gray arrow). Structures are numbered: the tower is structure number 55. Note that south is toward the top of the image.

an inversion wind, or katabatic flow, comes from southsouthwest, as indicated by the gray arrow. Under cyclonic flow, the winds are from the opposite direction. Only small platforms and shelters, including one at the foot of the tower, are located near the tower; these have minimal impact on sampled air flow. These small obstructions are located to the west of the buildings comprising the center of Concordia Station. The tower was instrumented facing into the dominant wind direction at six levels $(4.6,12.0,19.4$, 26.9, 34.2, and $43.4 \mathrm{~m}$ ) with thermohygrometers (Campbell HMP45C) sheltered in World Meteorological Organization-approved radiation shields and aerovanes (Young 45106).

[9] Data collection began 16 January 2008. The data were collected at $10 \mathrm{~s}$ intervals and averaged to $30 \mathrm{~min}$ periods before being stored. Wind direction was not averaged, but sampled and stored every minute. The temperature and humidity sensors were calibrated from $-40^{\circ} \mathrm{C}$ to $60^{\circ} \mathrm{C}$, but not operational below $-40{ }^{\circ} \mathrm{C}$. The 05106 aerovanes were cold-room tested, and proved to be operational below $-50^{\circ} \mathrm{C}$.

[10] The calibration of the temperature and humidity sensors limit this analysis. Since nighttime temperatures at Dome $\mathrm{C}$ drop below $-40^{\circ} \mathrm{C}$ in late January, this analysis is limited to summertime. In addition, the nonaspirated temperature sensors may be biased high by solar radiation at wind speeds less than $3 \mathrm{~m} \mathrm{~s}^{-1}$ [Huwald et al., 2009;
Georges and Kaser, 2002]. A correction for the solar bias is possible, but likely housing-specific. The bias and correction depend on the incoming solar radiation, surface albedo, and wind speed. We flag observed temperatures that may experience extreme biases during low wind speeds (i.e., $<3 \mathrm{~m} \mathrm{~s}^{-1}$ ), as well as provide an approximate correction for the bias based on the available literature. For these reasons, the temperature and humidity data here are effectively discontinuous. We present data when temperatures are below $-40^{\circ} \mathrm{C}$, and when winds are less than $3 \mathrm{~m} \mathrm{~s}^{-1}$, because the data are still useful in characterizing the main aspects of the summer ABL diurnal cycle at Dome C. The wind speed and direction observations themselves have no constraints over this time period.

\subsection{ECMWF Analyses}

[11] In the analysis to follow, we assume that the ECMWF analyses used here are representative of its current general performance under extreme conditions because ECMWF is not tuned for Antarctic plateau conditions. The case study approach used here is generally appropriate for evaluating the ability of the analyses to reproduce the timing and character of synoptic events with the mount of available data. The ECMWF analyses assimilate observations made worldwide into a meteorological model, so the chronology of the reconstructed meteorology should be realistic. The analyses themselves are only available at a 

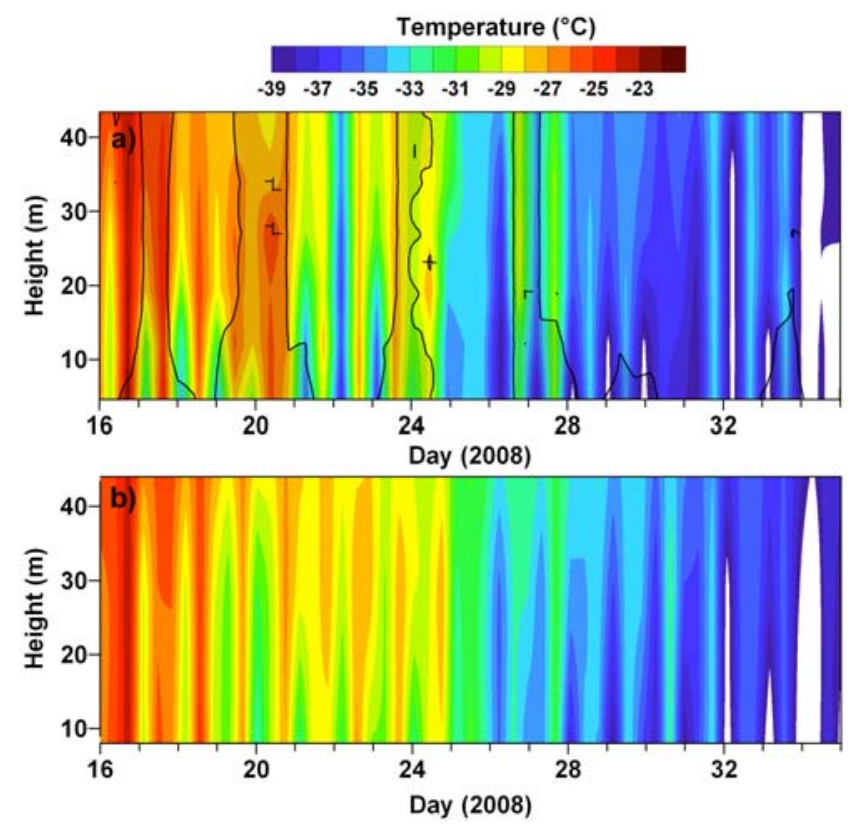

Figure 3. Temperature $\left({ }^{\circ} \mathrm{C}\right)$ in the lowest $45 \mathrm{~m}$ of the atmosphere over Dome C from 16 January 2008 through 4 February 2008. (a) Observed tower temperatures. The black contour lines and hatching indicate when wind is less than $3 \mathrm{~m} \mathrm{~s}^{-1}$, and therefore where temperatures may be significantly biased high by absorption of solar radiation. The white areas are where temperatures dipped below $-40^{\circ} \mathrm{C}$, the instrument detection limit. (b) ECMWF temperatures. We subtract $3^{\circ} \mathrm{C}$ from ECMWF temperatures to correct for a mean bias (see section 2). The $x$ axes are local time.

$6 \mathrm{~h}$ intervals. This is sufficient to capture the characteristics of the diurnal cycle, but not to precisely capture events of only a few hours in duration. ECMWF horizontal and vertical resolution are also coarse. The horizontal resolution is approximately $50 \mathrm{~km}$, but primitive equation variables are continuously defined through spherical harmonics. In the vertical at Dome $\mathrm{C}$, there are only two model levels within the lowest $45 \mathrm{~m}$ of the atmosphere, approximately 8-9 and 28-29 $\mathrm{m}$ above the surface during summer. For comparison with observations above $30 \mathrm{~m}$, the analyses are linearly interpolated between the second $(28-29 \mathrm{~m})$ and third $(57 \mathrm{~m})$ model levels. Analyses products at standard surface meteorological levels, $2 \mathrm{~m}$ for temperature and humidity and $10 \mathrm{~m}$ for wind, are also available but not used here since they add the complication of a boundary layer interpolation method onto the internal physics of the meteorological model. Finally, the model surface elevation at Dome $\mathrm{C}$ is $3230 \mathrm{~m}$ a.s.1., only $3 \mathrm{~m}$ different from the observed surface altitude.

\subsection{Radiosondes}

[12] The daily radiosonde (RS) data used in the following comparisons are from the Routine Meteorological Observation program (RMO, http://www.climantartide.it/) at Dome C. The RMO program launched Vaisala RS92 at 1200 UTC, 2000 LT, during the time period analyzed here. The meteorological analyses evaluated here assimilate the RMO RS data, but only at the standard meteorological pressure levels, none of which are located within the lowest $45 \mathrm{~m}$ of the atmosphere. The nearby observations on the Global Telecommunication System (GTS) accessed by weather prediction centers include two AWSs and the daily RMO RS launch.

[13] The HMP45C and the RS both use a Vaisala Humicap to measure relative humidity with respect to (w.r.t.) liquid water $\left(\mathrm{RH}_{\mathrm{w}}\right)$ [Anderson, 1995]. The ECMWF analyses of humidity are reported in terms of specific humidity. We convert these values into partial pressure and relative humidity w.r.t. to ice $\left(\mathrm{RH}_{\mathrm{i}}\right)$ using the method of Goff and Gratch [1945].

\subsection{Radiation Data}

[14] We use downwelling solar radiation data for Dome C to estimate the solar radiation bias in temperature. The data were taken and quality controlled by the Programma Nazionale Ricerche in Antartide, then distributed by the Baseline Surface Radiation Network (BSRN). The bias calculation (see below for details) requires upwelling solar radiation, so we multiply the downwelling solar radiation fluxes by an approximate clear-sky albedo for the Antarctic plateau, 0.80 [Grenfell et al., 1994].

\section{Results}

\subsection{Temperature Comparisons}

\subsubsection{Tower to ECMWF}

[15] Figure 3 shows the temperatures from tower observations and ECMWF below $45 \mathrm{~m}$ for 16 January to 4 February 2008. As stated above, the observed and model surface altitudes are very similar, so no correction for lapse rates have been applied in these comparisons. Temperature reports with winds less than $3 \mathrm{~m} \mathrm{~s}^{-1}$ are hatched because they are likely biased high by absorption of solar radiation by the nonaspirated housing. In the lower ABL, the ECMWF analyses overestimate temperature by approximately $3-4{ }^{\circ} \mathrm{C}$ relative to the tower observations. The bias is fairly constant diurnally (not shown), and is likely due to a low bias in the ECMWF surface albedo over Antarctica. ECMWF uses an albedo of 0.75 for all snow surfaces, but rather should use an albedo of 0.8 or higher for snow on the Antarctic plateau [e.g., Grenfell et al., 1994]. Once the albedo is increased, the bias of $3 \mathrm{~K}$ over the high southern latitudes is removed in ECMWF climate model runs (G. Balsamo, ECMWF, personal communication, 2008). The high bias in ECMWF temperature has been removed in Figure 3 for direct comparison to the observations reported here.

[16] Comparison of ECMWF to the present radiosonde data set at higher altitudes is not appropriate because the upper atmospheric daily radiosonde data at Dome $\mathrm{C}$ are fed into the GTS, and therefore assimilated into the ECMWF analyses. However, a comparison of independent radiosonde soundings taken over Dome $\mathrm{C}$ to concurrent ECMWF analyses show a near-surface temperature bias similar to that reported here, but no significant bias in the free atmosphere [Sadibekova et al., 2006, Figure 1].

[17] The observations show that much of the diurnal variability in temperature occurs within the lowest $15-20 \mathrm{~m}$ (Figures $3 \mathrm{a}$ and $4 \mathrm{a}$ ). This was also shown by Hudson and 

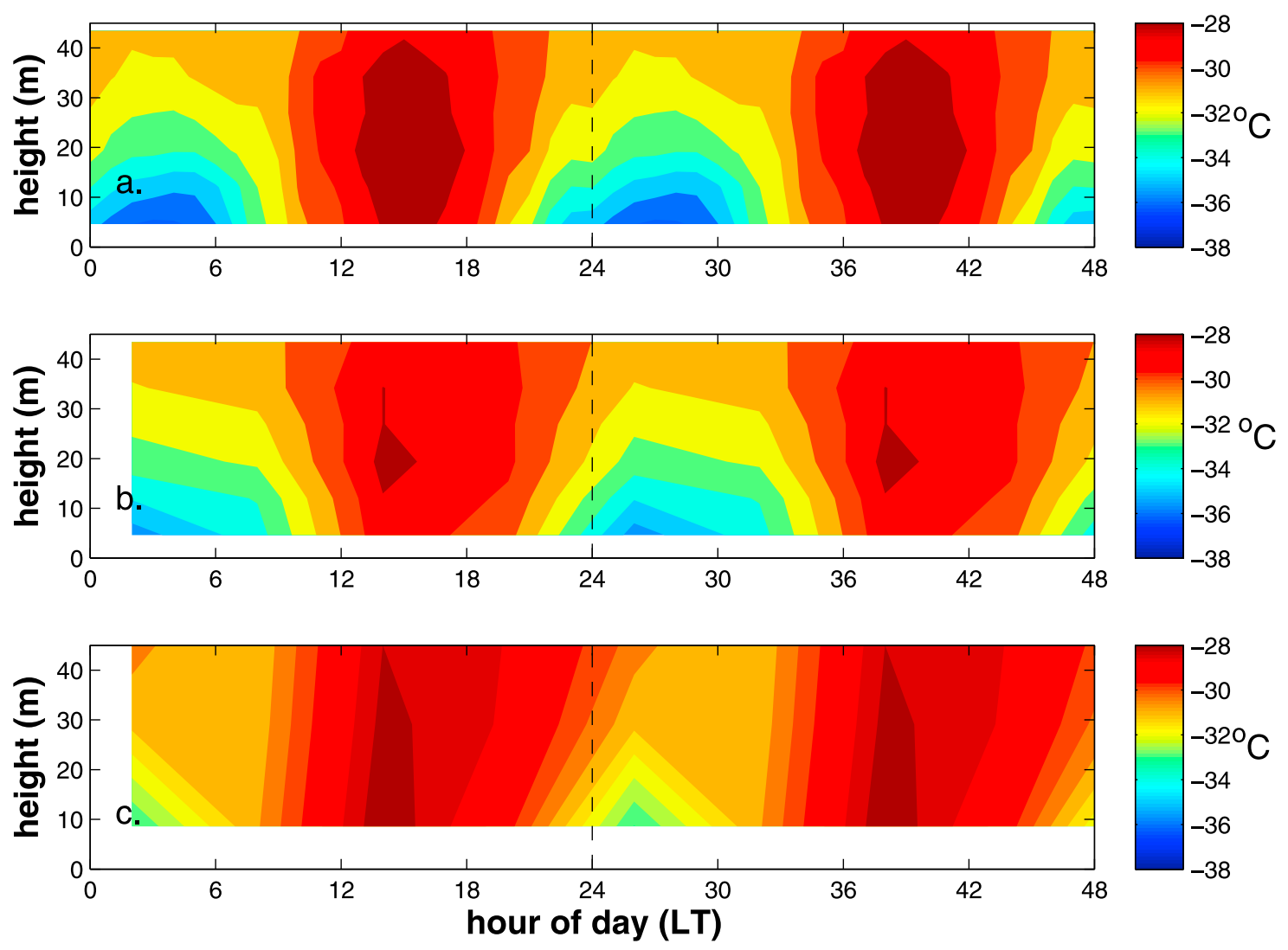

Figure 4. Diurnal cycle of near-surface temperature at Dome C for 16 January 2008 through 31 January 2008 from (a) the tower observations, (b) the tower observations subsampled to $6 \mathrm{~h}$, and (c) ECMWF analyses. Diurnal cycle is repeated for clarity.

Brandt [2005, Figure 22] and Aristidi et al. [2005, Figure 11], through the same, high temporal resolution RS profiles. The ECMWF analyses (Figures $3 \mathrm{~b}$ and $4 \mathrm{c}$ ) reproduce the diurnal cycle in temperature, although it is weaker than observed. For direct comparison to the ECMWF analyses, we have subsampled and averaged the hour of tower data around the ECMWF analyses (Figure 4b). The cooling trend over the full period is reproduced in the analyses, and some of the shorter-term variability is also captured. However, the near-surface day-to-day variability from ECMWF is generally muted relative to the observations, and the cold nighttime temperatures in ECMWF typically extend higher in the atmosphere than in the observations.

[18] It is possible that some of the variability in the observations are due to an instrument bias. For example, short warm events on days 17, 20, and 26 are not fully reproduced in the ECMWF analyses. On day 20, the event appears at all tower levels simultaneously, and coincides with very low wind speeds near local noon (section 3.3). It seems that this is an example of an extreme a solar radiation bias event [e.g., Huwald et al., 2009; Georges and Kaser, 2002]. Figure 5 shows the approximate bias in temperature at the top and bottom of the tower based on the solar radiation bias correction developed by Huwald et al. [2009]. At the base of the tower during January, the bias typically ranges from $1 \mathrm{~K}$ to almost $4 \mathrm{~K}$. The bias is less at the top of the tower because it is normally more windy at the top of the tower. The maximum estimated bias in this study occurs on day 20 ; it is almost $40 \mathrm{~K}$. This is clearly an unphysical bias, indicating that these corrections are likely housingspecific, particularly when wind speeds are low. The correction is inversely proportional to wind speed, and therefore very sensitive to small changes at low wind speed values. In addition to the extreme bias at low wind speeds, there is still a nonzero bias predicted by this correction during very high wind speed events (i.e., day 25). A future priority for our site efforts at Dome $\mathrm{C}$ is to develop similar bias estimates for the temperature sensor and housings deployed there.

[19] Figure 6 compares the details of the observations at the lowest and highest tower levels. A strong diurnal cycle is shown close to the surface, which is damped at the top of the tower. Thus, in spite of the very high surface albedo (0.8) [Grenfell et al., 1994], the diurnal cycle of solar radiation is sufficient to induce a significant diurnal cycle in near-surface temperature. Argentini et al. [2005] and Hudson and Brandt [2005] show that the maximum nearsurface temperature lags solar noon by only an hour or two; this delay is smaller than typically found at midlatitudes due to low latent heat fluxes at East Antarctic plateau temperatures, and the low thermal diffusivity of the cold snow surface. Similarly, the coldest temperatures are observed approximately $1 \mathrm{~h}$ after midnight.

[20] The observations show weak lapse rates similar to those observed during summer at the South Pole [Hudson and Brandt, 2005]. In contrast to the South Pole, a geographic singularity, the solar diurnal cycle results in sum- 


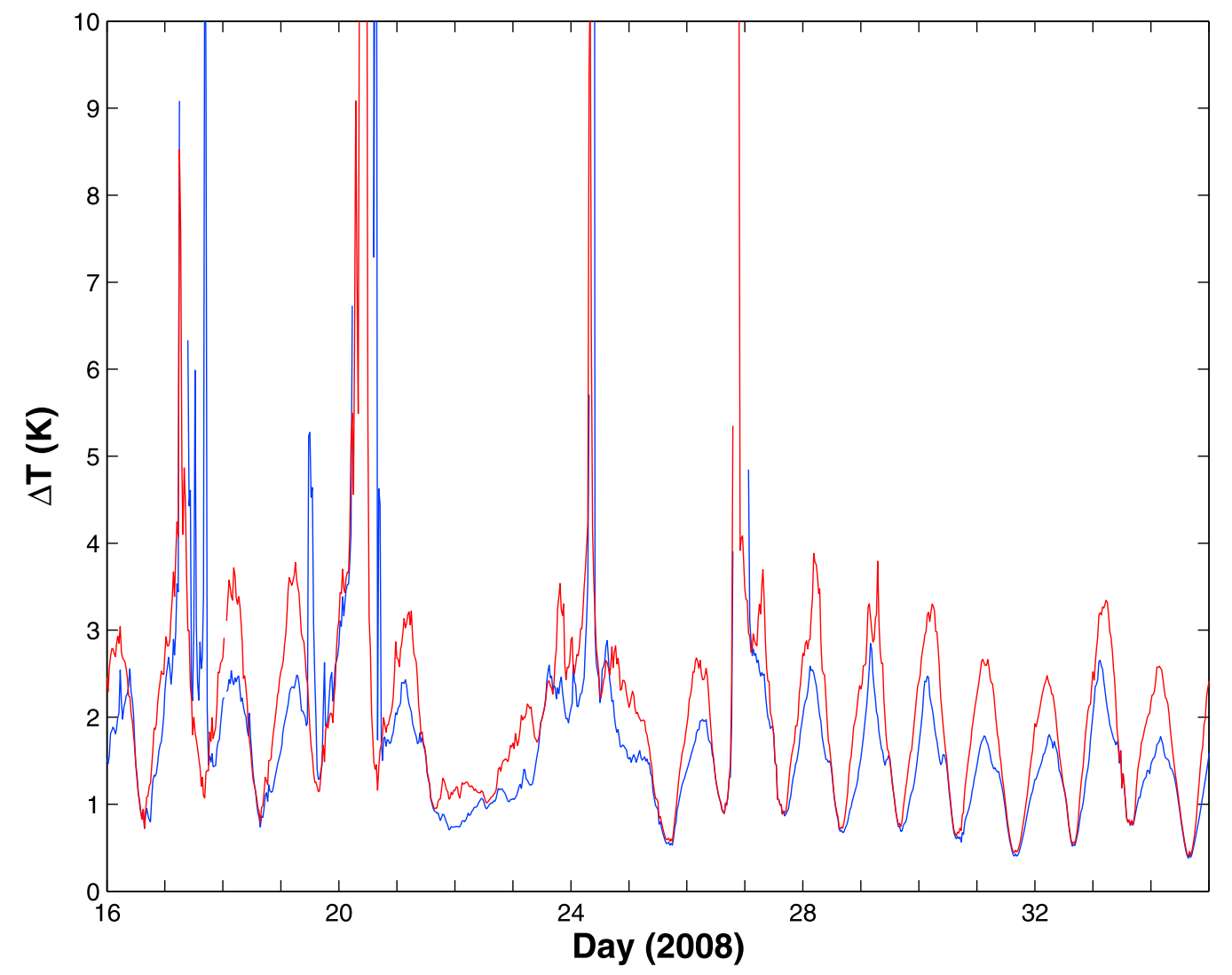

Figure 5. Predicted solar radiation bias in observed temperature at $4.6 \mathrm{~m}$ (red curve) and $43.4 \mathrm{~m}$ (blue curve). The bias is estimated based on the formula determined by Huwald et al. [2009] using observations of upwelling solar radiation, horizontal winds, and temperature.

mertime nocturnal inversion strength between $3 \mathrm{~K}$ and $7 \mathrm{~K}$ $(0.75 \mathrm{~K}$ to $1.75 \mathrm{~K}$ per $10 \mathrm{~m})$. We find no clear correlation between wind speed (section 3.2) and inversion strength [e.g., Town and Walden, 2009], but it is likely this time series is not yet long enough for such analysis.

[21] Beyond the prescription of diurnal solar variation, ECMWF is constrained by assimilated satellite data and

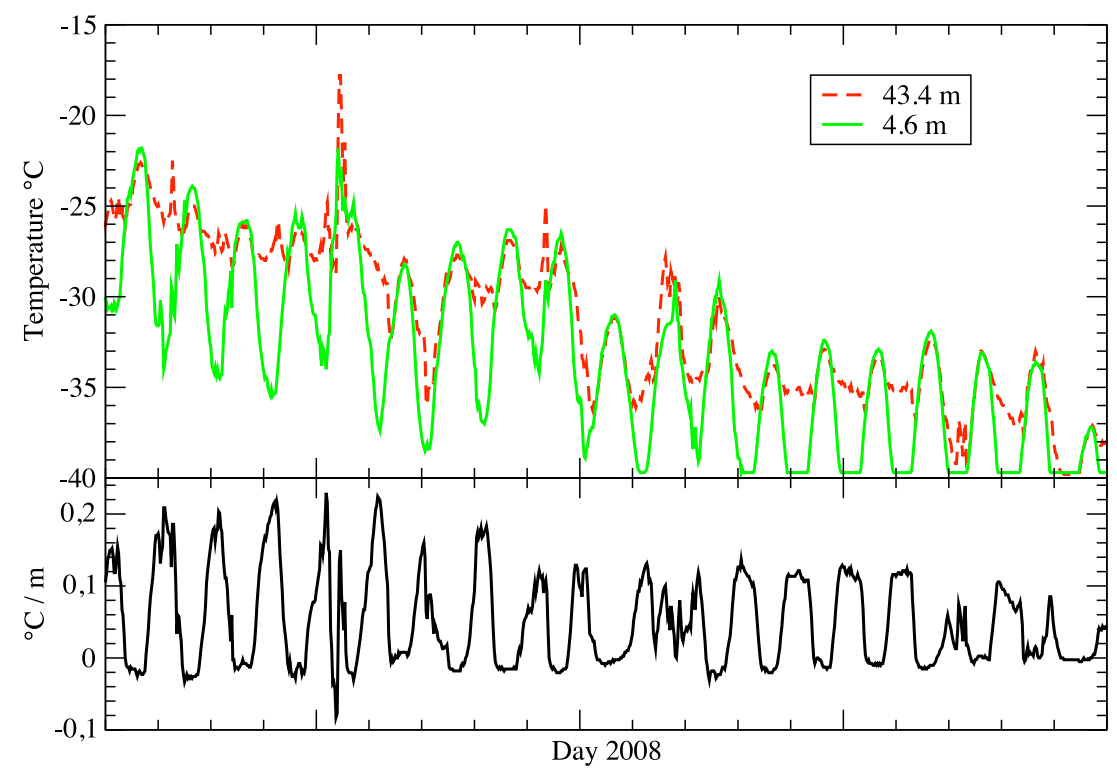

Figure 6. (top) Time series of atmospheric temperature $\left({ }^{\circ} \mathrm{C}\right.$ ) at Dome $\mathrm{C}$ recorded at $4.6 \mathrm{~m}$ (green) and $43.5 \mathrm{~m}$ (red) on the tower. (bottom) Time series of vertical gradient of temperature from $4.6 \mathrm{~m}$ and $43.5 \mathrm{~m}$ values. 


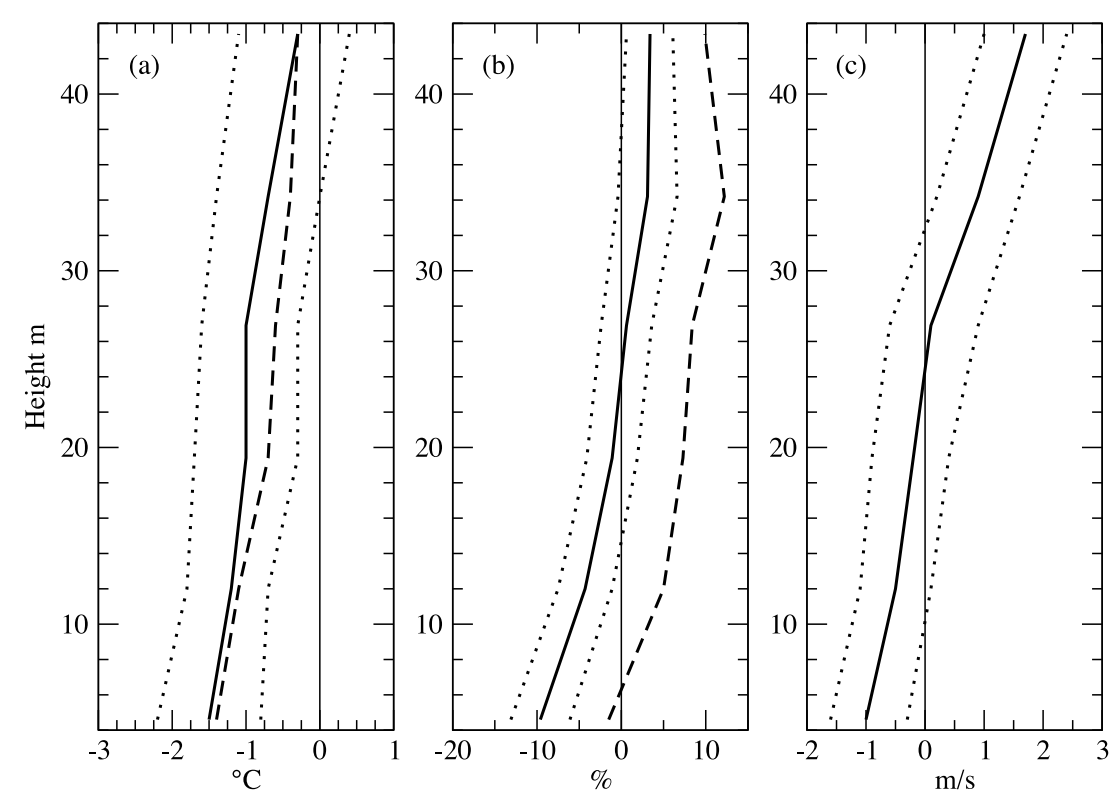

Figure 7. Mean residual between radiosonde profiles and tower observations (solid line; RS minus obs) with $95 \%$ confidence (dotted line) at Dome C. (a) Temperature $\left({ }^{\circ} \mathrm{C}\right)$, (b) relative humidity $(\%)$, and (c) wind $\left(\mathrm{m} \mathrm{s}^{-1}\right)$. The thick dashed lines are mean residuals excluding cases when winds are less than $3 \mathrm{~m} \mathrm{~s}^{-1}$. For relative humidity, we also show the wind speed-filtered data with a $9 \%$ shift to correct for low biases due to radiosonde age; see text.

Antarctic station observations, which are likely essential to its qualified success at reproducing the synoptic chronology in temperature.

\subsubsection{Tower to Radiosonde}

[22] Figure 7 shows a comparison between the tower data and the first few seconds, i.e., the first few tens of meters, of flight from the RS soundings. Lag corrections to RS temperature profiles [Mahesh et al., 1997] are no longer necessary for the newer RS92 sondes [Rowe et al., 2008]. There is a cold bias of more than $1^{\circ} \mathrm{C}$ close to the surface (instrument uncertainty $= \pm 0.5^{\circ} \mathrm{C}$ at $-40^{\circ} \mathrm{C}$ ) [Vaisala, 2005]. However, the bias reduces to an insignificant value at the top of the tower. It is not likely that they are still thermally adjusted to warm, indoor temperatures before launch [e.g., Hudson et al., 2004], because that would result in a positive bias in the RS temperatures at the surface. One possible explanation is that the tower observations suffer from solar heating, but are better ventilated with height. This is corroborated by Figure 5 .

\subsection{Humidity Comparisons}

\subsubsection{Tower to ECMWF}

[23] Figure 8 shows $\mathrm{RH}_{\mathrm{i}}$ from the tower data and the ECMWF analyses. The diurnal cycle is clear, but its magnitude is slightly overestimated in the analyses (Figure 9). Near-surface turbulent fluxes from ECMWF (not shown) indicate that the latent heat flux is positive (sublimation) during day and negative (deposition) during night. This is a function of vertical gradients in specific humidity in the model and consistent with the observed diurnal cycle of humidity at the lowest tower level (Figure 10). If the absolute humidity were constant, the diurnal cycle in temperature alone would cause $\mathrm{RH}_{\mathrm{i}}$ to vary. However, Figure 10 shows that the observed humidity of the lower
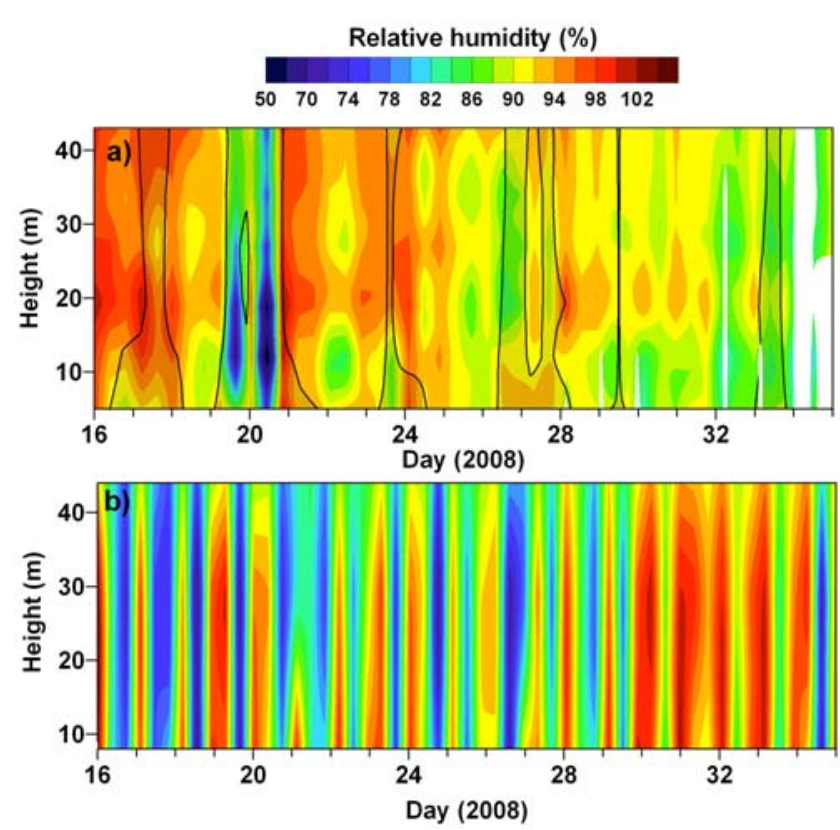

Figure 8. Relative humidity w.r.t. ice (\%) in the lowest $45 \mathrm{~m}$ of the atmosphere over Dome C from 16 January 2008 through 4 February 2008. (a) Tower observations. The black contour lines and hatching indicate when wind is less than $3 \mathrm{~m} \mathrm{~s}^{-1}$, and therefore where temperatures may be biased high by absorption of solar radiation. The white areas are where temperatures dipped below $-40^{\circ} \mathrm{C}$, the instrument detection limit. (b) ECMWF analyses. The $x$ axis is local time. 

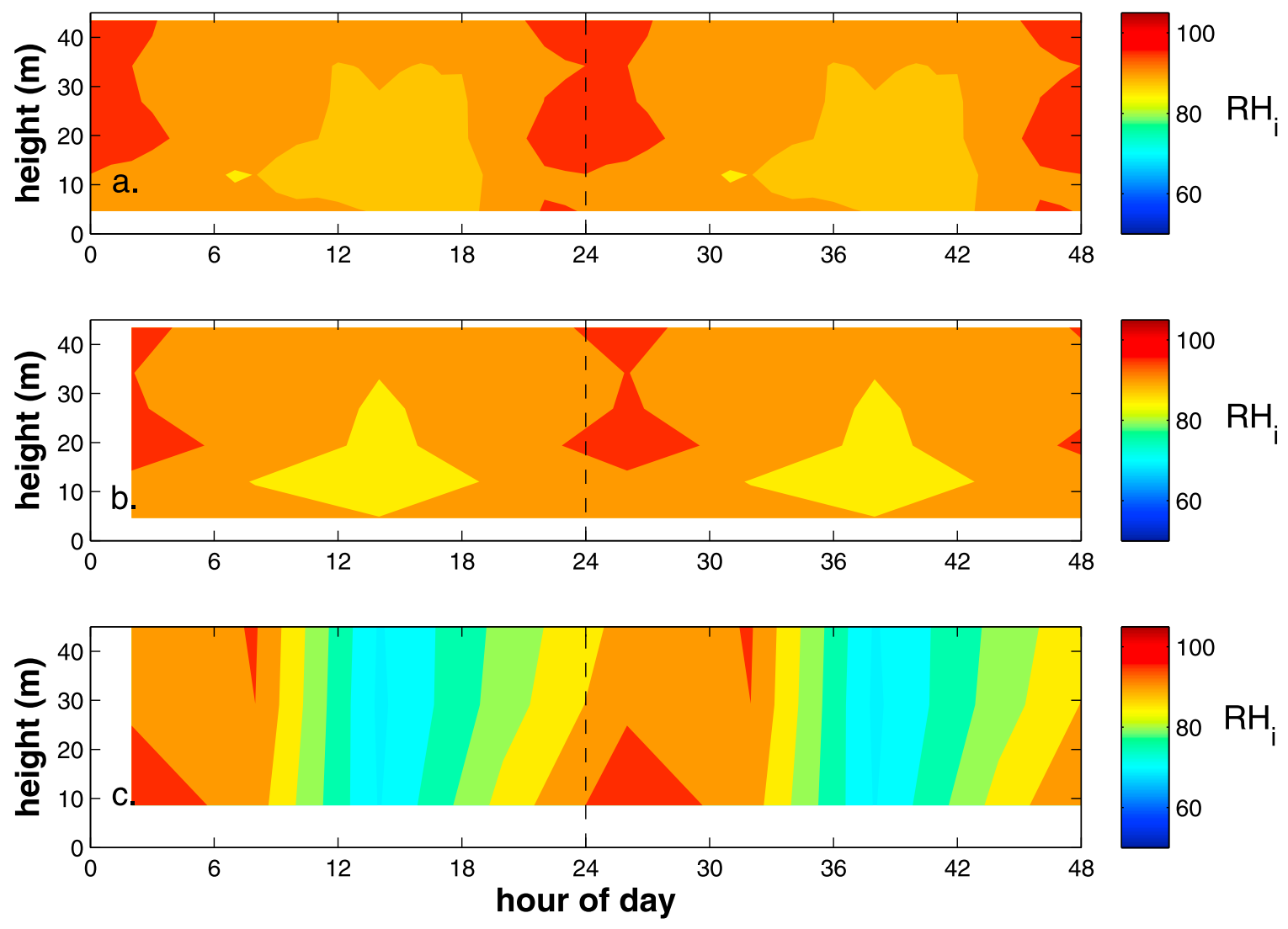

Figure 9. Diurnal cycle of near-surface $\mathrm{RH}_{i}$ at Dome $\mathrm{C}$ for 16 January 2008 through 31 January 2008 from (a) the tower observations, (b) the tower observations subsampled to $6 \mathrm{~h}$, and (c) ECMWF analyses. Diurnal cycle is repeated for clarity.

ABL is actually larger during the day than the night, as well as a significant vertical gradient in humidity that develops each night. This indicates one or both of the following: a shift of a significant amount of water from vapor to condensed phase (liquid or solid), or significant diurnal latent heat fluxes between the surface and the atmosphere. [24] We further investigate the discrepancy in magnitude of $\mathrm{RH}_{\mathrm{i}}$ diurnal cycle by computing the diurnal cycle of

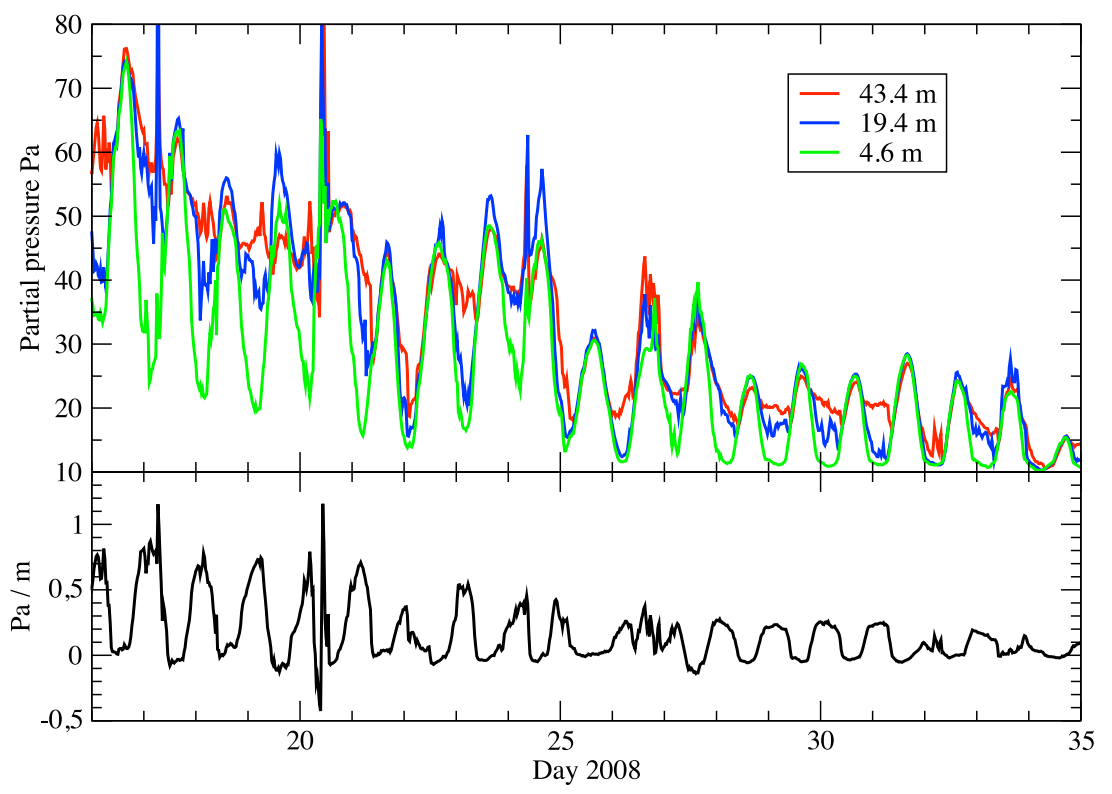

Figure 10. (top) Time series of absolute humidity at Dome C (Pa) recorded at $4.6 \mathrm{~m}$ (green), $19.4 \mathrm{~m}$ (blue), and $43.5 \mathrm{~m}$ (red) on the tower. (bottom) Time series of vertical gradient of humidity from $4.6 \mathrm{~m}$ and $43.5 \mathrm{~m}$ values. 

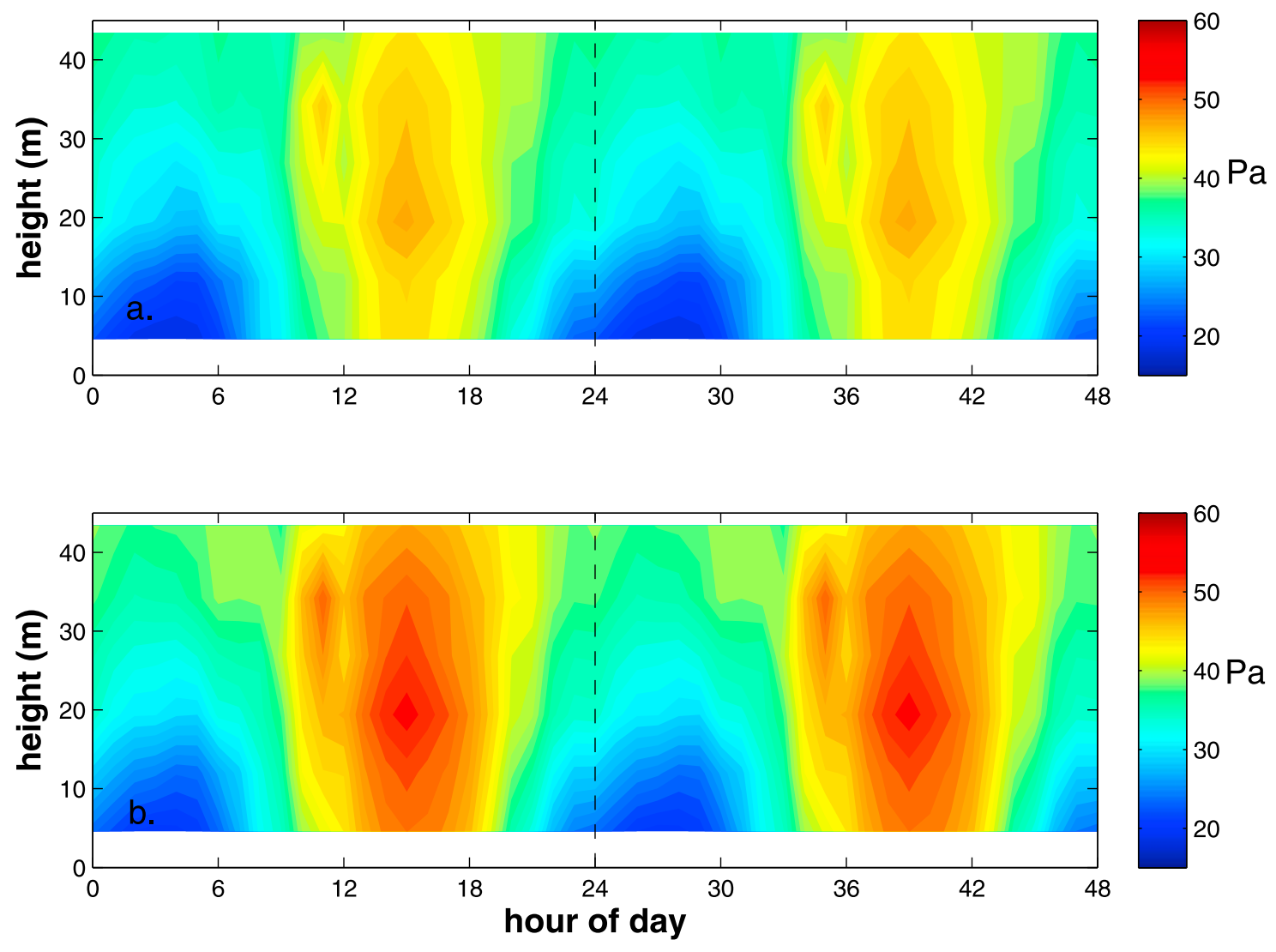

Figure 11. Diurnal cycle of (a) near-surface vapor pressure and (b) saturation vapor pressure from the $45 \mathrm{~m}$ tower at Dome C for 16 January 2008 through 31 January 2008. Diurnal cycle is repeated for clarity.

vapor pressure and saturation vapor pressure from both the tower data and ECMWF output (Figures 11 and 12). Figures 11a and 12a show the actual vapor pressure, and Figures $11 \mathrm{~b}$ and $12 \mathrm{~b}$ show the saturation vapor pressure. The observed vapor pressure is much lower than in the ECMWF output, due primarily to the temperature bias in ECMWF. The ECMWF vapor pressure diurnal cycle over this time period (16 January 2008 to 31 January 2008) in the lowest level is approximately $11 \mathrm{~Pa}$, whereas it is approximately $25 \mathrm{~Pa}$ at similar levels in the observations. On the other hand, the magnitude of the diurnal cycle in saturation vapor pressure is similar in the observations and ECMWF, approximately $30 \mathrm{~Pa}$. Therefore, the large $\mathrm{RH}_{\mathrm{i}}$ diurnal cycle in ECMWF is due primarily to small vapor fluxes in the analyses.

[25] The $\mathrm{RH}_{\mathrm{i}}$ occasionally reaches values above saturation in the observations. However, such small supersaturations values are uncertain [Vaisala, 2005]. Observations of near-surface liquid water fog and frequent frost and rime deposition on metal and plastic structures confirm that the atmosphere is often near or above saturation w.r.t. ice. Supersaturation w.r.t. ice has been observed elsewhere on the Antarctic plateau [Hudson et al., 2004; Town et al., 2005]. In addition, the air over the Antarctic plateau is very clean, with very little cloud condensation nuclei [Jourdain et al., 2008], so supersaturation w.r.t. ice and homogeneous freezing are distinct possibilities for much of the year.

\subsubsection{Tower to Radiosonde}

[26] Lag corrections to the humidity measurements are not necessary during this time period because the temperatures in the lower ABL during launch were above $-47^{\circ} \mathrm{C}$ [Miloshevich et al., 2004]. No solar bias correction was applied to the humidity data because the large solar zenith angles at the time of the routine RS launches $\left(77.6^{\circ}-82.5^{\circ}\right)$ likely make these corrections unnecessary [Rowe et al., 2008]. Before correction for any biases, the relative humidity is underestimated by the RS in the lower levels relative to the tower observations (Figure 7b). For this type of humicap sensor, however, it is thought that an age-related contamination low bias exists [Miloshevich et al., 2004].

[27] If no bias correction is necessary, then the solid line shown in Figure $7 \mathrm{~b}$ can be explained by efficient in-flight ventilation. It is possible that the RS was brought suddenly from a warmer preparation chamber to the outdoors. If so, it has been shown that this can cause a temporary low bias in $\mathrm{RH}_{\mathrm{i}}$ as the RS equilibrates to the ambient atmosphere [Hudson et al., 2004]. This effect would be mitigated by in-flight ventilation.

[28] The dry-bias correction developed for RS90 radiosondes by Miloshevich et al. [2004] is applicable to the newer RS92 radiosondes [e.g., Cadt-Pereira et al., 2009]. The RS92 sondes used during this time period at Dome C are approximately 2 years old, which results in a correction factor of $9 \%$ relative increase in relative humidity 

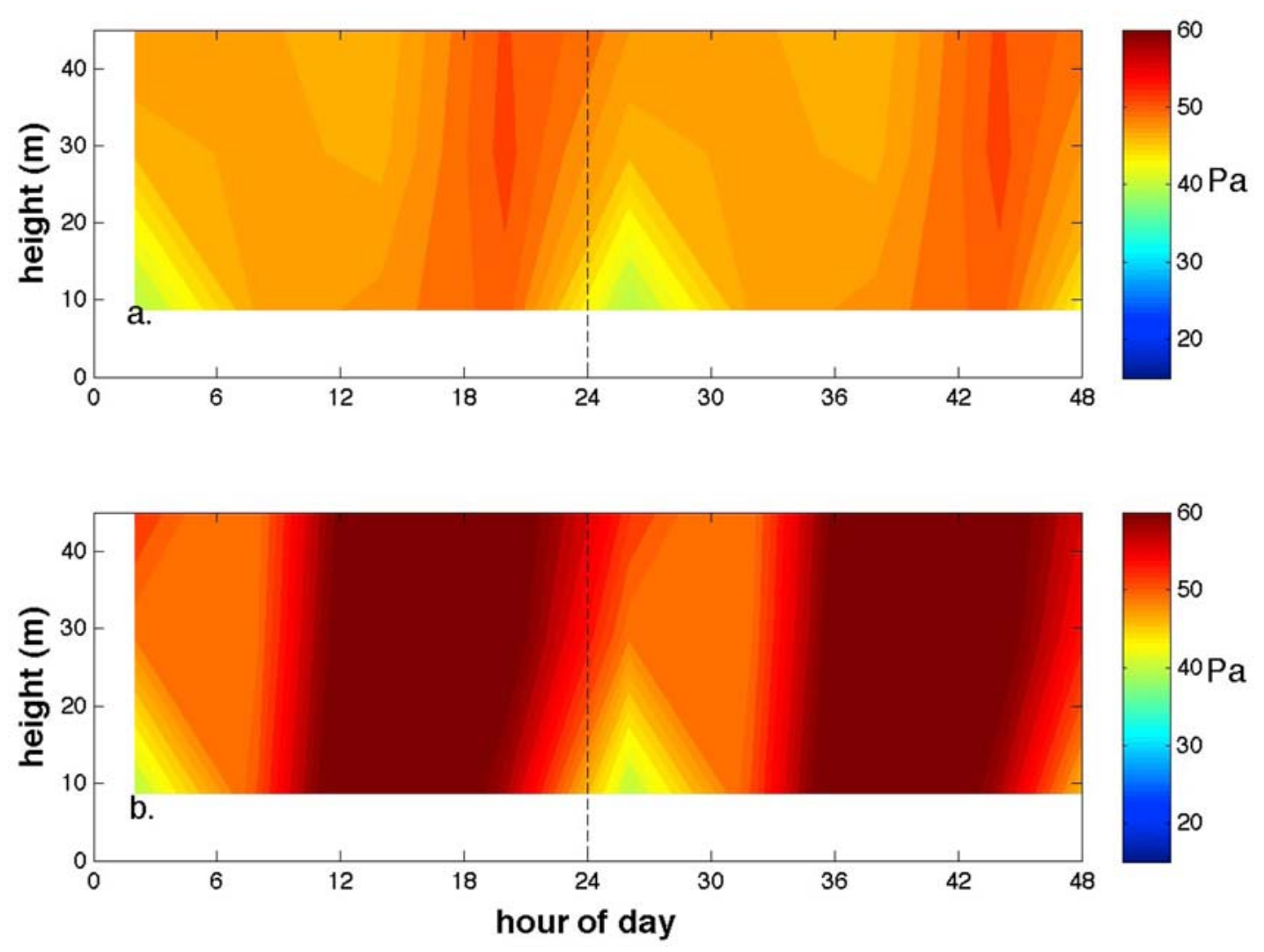

Figure 12. Diurnal cycle of (a) near-surface vapor pressure and (b) saturation vapor pressure from ECMWF analyses at Dome C for 16 January 2008 through 31 January 2008. Diurnal cycle is repeated for clarity.

[Miloshevich et al., 2004]. The correction we apply is the same found for RS92 sondes of a few months age launched at Dome C [Rowe et al., 2008]. Longer-term lag corrections to RS humidity profiles in cold environments [e.g., Hudson et al., 2004] no longer seem necessary for the newer RS92 sondes [Rowe et al., 2008]. The correction obviously improves the agreement between tower and RS data at the surface and correspondingly degrades the agreement at $45 \mathrm{~m}$ elevation.

\subsection{Wind Speed and Direction}

\subsubsection{Tower to ECMWF}

[29] Figure 13 shows the comparison of the profiles and the evolution of wind speed from the tower sensors and the ECMWF analyses. A regular diurnal cycle does not emerge quite as clearly as for temperature and humidity. However, Figure 14 indicates that the observed wind speed and wind direction are both significantly different from each other around midday and midnight, respectively. Wind shear builds at night because the temperature inversion suppresses turbulent mixing of momentum. Conversely, convective mixing during the day [Argentini et al., 2005] produces a barotropic-like homogeneity of the wind speed profile. For wind direction, convection again results in a homogeneous surface layer, while at night an Ekman spiral develops, as observed by Kuhn et al. [1977] at Plateau Station. In the ECMWF analyses, the 1800 UT time step (0200 local time) is when the strongest vertical gradients occur. However, the


Figure 13. Horizontal wind speed $\left(\mathrm{m} \mathrm{s}^{-1}\right)$ in the lowest $45 \mathrm{~m}$ of the atmosphere over Dome C from 16 January 2008 through 4 February 2008. (a) Tower observations. (b) ECMWF analyses. 



Figure 14. Mean profiles of (a) horizontal wind speed and (b) direction. The tower observations are those from 0200 (green curve) and 1400 (red, dashed curve) local time. The ECMWF profiles are from 0200 (blue curve) local time.

observed nocturnal wind shear is underestimated and the Ekman spiral is not reproduced.

[30] Assuming that the observed gradient of wind direction reflects the lower part of an Ekman spiral, then a simple first-order calculation [Stull, 1988, pp. 206-214] indicates that the mean eddy viscosity in this layer is less than $1 \mathrm{~m}^{2} \mathrm{~s}^{-1}$. This is consistent with the values reported in the literature for very stable boundary layers [Stull, 1988]. The fact that the ECMWF does not reproduce the observed spiral in wind direction or the observed wind shear suggests that the turbulent mixing may be overestimated in ECMWF. The limited agreement in timing between the ECMWF analyses of wind speed and the tower observations, and the vertical resolution in the ECMWF analyzes, make the level of disagreement in wind shear shown here not surprising despite the parameterization of turbulent diffusion in ECMWF.

\subsubsection{Tower to Radiosonde}

[31] The only clear information obtained by comparing tower and RS data for wind (Figure 7c) is a confirmation that the near-surface wind speeds cannot be estimated by radiosondes so shortly after launch. The balloon-sonde combination is still perturbed by launch in the lowest $45 \mathrm{~m}$ of the atmosphere.

\section{Conclusions}

[32] Continuous summertime measurements of temperature, humidity, and wind speed and direction have been carried out at six levels of a $45 \mathrm{~m}$ tower at Concordia station, Dome C, Antarctica. These data have been compared to concurrent RS soundings and ECMWF analyses. The new data set is not only important for understanding the climate of the Antarctic plateau, but we have also shown that it provides an extreme test of the ability of meteorological model physics and parameterizations.

[33] The data set was limited by sensor calibration and operation range, yet, the three week data set proves suffi- cient to characterize a number of summertime phenomena on the high Antarctic plateau. We report observations of: (1) strong nocturnal inversions of more than $1 \mathrm{~K}$ per $10 \mathrm{~m}$ that breakdown during the day due to convective mixing; (2) occasional supersaturation w.r.t. ice at night; (3) strong wind shear at night that reflects weak turbulent mixing of momentum; (4) a classic Ekman spiral under surface-based temperature inversion conditions. Due to insufficient temporal resolution, none of these characteristics may be adequately sampled by the daily RS soundings carried out at Dome C. The RS soundings themselves appear to be significantly biased with respect to the lowest tower measurements. However, the near-surface RS data are not assimilated into weather analysis and prediction centers like the ECMWF, and so have no effect on their products.

[34] Evaluation of ECMWF for this time period shows a $3-4^{\circ} \mathrm{C}$ warm bias in the analyses relative to the tower observations, likely due to a low bias in the surface albedo. ECMWF also shows a muted diurnal cycle in temperature relative to observations, with smaller vertical temperature gradients that reach higher in the ABL. The analyses reproduce the general cooling trend over the observing period. Relative humidity is less well reproduced than temperature. In particular, the amplitude of the diurnal cycle of $\mathrm{RH}_{\mathrm{i}}$ is too strong because the diurnal range of vapor pressure is too small in the ECMWF output. Wind is the least well reproduced variable, but this is where shortcomings in parameterizing very stable boundary layers are expected be most apparent.

[35] The tower observations are also not without their own possible biases. Solar heating of the tower temperature measurements are an unresolved issue. This effect is magnified over snow surfaces because the high albedo of snow causes the instrument shelters to be heated by upwelling solar radiation. The potential bias also depends on sensor type, wind speed, and cloudiness. Corrections for these effects generally make all ECMWF the comparisons result 
in a slightly higher warm bias in the ECMWF comparisons but improve the near-surface comparisons between radiosondes and tower observations.

[36] Acknowledgments. The Concordia station is jointly operated by IPEV and PNRA. Meteorological instruments were funded by the French Institut National des Sciences de l'Univers program "EquipementTroposphère-Concordia." Data analysis was carried out as part of the "LEFE-CHAT-SOUFRE" and "LEFE-EVE-CHARMANT" projects and as part of the THORPEX/IPY CONCORDIASI Program. Radiation data were provided by the Baseline Surface Radiation Network.

\section{References}

Anderson, P. S. (1995), Mechanism for the behavior of hydroactive materials used in humidity sensors, J. Atmos. Oceanic Technol., 12, 662-667.

Argentini, S., A. Viola, A. M. Sempreviva, and I. Petenko (2005), Summer boundary-layer height at the plateau site of Dome C, Antarctica, Boundary Layer Meteorol., 115, 409-422.

Aristidi, E., et al. (2005), An analysis of temperatures and wind speeds above Dome C, Antarctica, Astron. Astrophys., 430, 739-746.

Bailey, D. A., and A. H. Lynch (2000), Development of an Antarctic Regional Climate Model, Part II: Station validation and surface energy balance, J. Clim., 13, 1351-1361.

Briegleb, B. P., and D. H. Bromwich (1998), Polar radiation budgets of the NCAR CCM3, J. Clim., 11, 1246-1268.

Cadt-Pereira, K. E., M. W. Shephard, D. D. Turner, E. J. Mlawer, S. A. Clough, and T. J. Wagner (2009), Improved daytime column-integrated precipitable water vapor from Vaisala radiosonde humidity sensors, J. Atmos. Oceanic Technol., 25, 873-883.

Cassano, J. J., T. R. Parish, and J. C. King (2001), Evaluation of turbulent surface flux parameterizations for the stable surface layer over Halley, Antarctica, Mon. Weather Rev., 129, 26-46.

Cullather, R. I., D. H. Bromwich, and R. W. Grumbine (1997), Validation of operational numerical analyses in Antarctic latitudes, J. Geophys. Res., $102,13,761-13,784$.

Dalrymple, P. C., H. H. Lettau, and S. H. Wollaston (1966), South Pole Micrometeorology Program: Data analysis, in Studies in Antarctic Meteorology, Antarct. Res. Ser., vol. 9, edited by M. J. Rubin, pp. $13-$ 58, AGU, Washington, D. C.

Genthon, C., and A. Braun (1995), ECMWF analyses and prediction of the surface climate of Greenland and Antarctica, J. Clim., 8, 2324-2332.

Georges, C., and G. Kaser (2002), Ventilated and unventilated air temperature measurements for glacier? Climate studies on a tropical high mountain site, J. Geophys. Res., 107(D24), 4775, doi:10.1029/2002JD002503.

Georgiadis, T., S. Argentini, G. Mastrantonio, A. Viola, G. Dargaud, and R. Sozzi (2002), Boundary layer convective-like activity at Dome Concordia, Antarctica, Nuovo Cimento Soc. Ital. Fis. C, 25, 425-431.

Goff, J. A., and S. Gratch (1945), Thermodynamics properties of moist air, Trans. Am. Soc. Heat. Vent. Eng., 51, 125-157.

Grenfell, T. C., S. G. Warren, and P. C. Mullen (1994), Reflection of solar radiation by the Antarctic snow surface at ultraviolet, visible, and nearinfrared wavelengths, J. Geophys. Res., 99, 18,669-18,684.

Hines, K. M., R. W. Grumbine, D. H. Bromwich, and R. I. Cullather (1999), Surface energy balance of the NCEP MRF and NCEP-NCAR reanalysis in antarctic latitudes during FROST, Weather Forecasting, 14, $851-866$.

Hines, K. M., D. H. Bromwich, P. J. Rasch, and M. J. Iacono (2004), Antarctic clouds and radiation within the NCAR climate models, J. Clim., $17,1198-1212$.

Hudson, S. R., and R. E. Brandt (2005), A look at the surface-based temperature inversion on the Antarctic Plateau, J. Clim., 18, 1673-1696.

Hudson, S. R., M. S. Town, V. P. Walden, and S. G. Warren (2004), Temperature, humidity, and pressure response of radiosondes at low temperatures, J. Atmos. Oceanic Technol., 21, 825-836.

Huwald, H., C. W. Higgins, M.-O. Boldi, E. Bou-Zeid, M. Lehning, and M. B. Parlange (2009), Albedo effect on radiative errors in air temperature measurements, Water Resour. Res., 45, W08431, doi:10.1029/ 2008WR007600.

Jourdain, B., S. Preunkert, O. Cerri, H. Castebrunet, R. Udisti, and M. Legrand (2008), Year-round record of size-segregated aerosol composition in central Antarctica (Concordia station): Implication for the degree of fractionation of sea-salt particles, J. Geophys. Res., 113, D14308, doi:10.1029/2007JD009584.

King, J. C. (1990), Some measurements of turbulence over an antarctic ice shelf, Q. J. R. Meteorol. Soc., 116, 379-400.

King, J. C., and P. S. Anderson (1994), Heat and water vapour fluxes and scalar roughness lengths over an Antarctic ice shelf, Boundary Layer Meteorol., 69, 101-121.
King, J. C., and W. M. Connolley (1997), Validation of the surface energy balance over the Antarctic ice sheets in the U.K. Meteorological Office Unified Climate Model, J. Clim., 10, 1273-1287.

King, J. C., S. Argentini, and P. Anderson (2006), Contrasts between the summertime surface energy balance and boundary layer structure at Dome C and Halley stations, Antarctica, J. Geophys. Res., 111, D02105, doi:10.1029/2005JD006130.

Kuhn, M., H. H. Lettau, and A. J. Riordan (1977), Stability-related wind spiraling in the lowest 32 meters, in Meteorological Studies at Plateau Station, Antarctica, Antarct. Res. Ser., vol. 25, edited by J. A. Businger, pp. 93-111, AGU, Washington, D. C

Lettau, H. H., and W. Schwerdtfeger (1971), Antarctic atmosphere as a test tube for meteorological theories, in Research in Antarctica, pp. 443-475, Am. Assoc. for Adv. of Sci., Washington, D. C.

Mahesh, A., V. P. Walden, and S. G. Warren (1997), Radiosonde temperature measurements in strong inversions: Correction for thermal lag based on an experiment at the South Pole, J. Atmos. Oceanic Technol., 14, 45-53. Miloshevich, L. M., H. Vömel, D. N. Whiteman, B. M. Lesht, F. J. Schmidlin, and F. Russo (2004), Absolute accuracy of water vapor measurements from six operational radiosonde types launched during AWEX-G and implications for AIRS validation, J. Geophys. Res., 111, D09S10, doi:10.1029/2005JD006083.

Miloshevich, L. M., H. Vömel, D. N. Whiteman, and T. Leblanc (2009), Accuracy assessment and correction of Vaisala RS92 radiosonde water vapor measurements, J. Geophys. Res., 114, D11305, doi:10.1029/ 2008JD011565.

Rowe, P. M., L. M. Miloshevich, D. D. Turner, and V. P. Walden (2008), Dry bias in Vaisala RS90 radiosonde humidity profiles over Antarctica, J. Atmos. Oceanic Technol., 25, 1529-1541.

Sadibekova, T., E. Fossat, C. Genthon, G. Krinner, E. Aristidi, K. Agabi, and M. Azouit (2006), On the atmosphere for astronomers above Dome C, Antarctica, Antarct. Sci., 18, 437-444.

Schwerdtfeger, W. (1970), The climate of the Antarctic, in World Survey of Climatology, vol. 14, edited by E. Landsberg, pp. 253-355, Elsevier, Amsterdam.

Schwerdtfeger, W. (1984), Weather and Climate of the Antarctic, 261 pp., Elsevier, Amsterdam.

Stull, R. B. (Ed.) (1988), An Introduction to Boundary Layer Meteorology, 666 pp., Kluwer Acad., Boston, Mass.

Town, M. S., and V. P. Walden (2009), Surface energy budget over the South Pole and turbulent heat fluxes as a function of an empirical bulk Richardson number, J. Geophys. Res., 114, D22107, doi:10.1029/ 2009JD011888.

Town, M. S., V. P. Walden, and S. G. Warren (2005), Cloud cover climatology for the South Pole from surface-based infrared radiation measurements, paper presented at Eighth Conference on Polar Meteorology and Oceanography, Am. Meteorol. Soc., San Diego, Calif.

Travouillon, T., M. C. B. Ashley, M. G. Burton, J. W. V. Storey, and R. F. Loewenstein (2003), Atmospheric turbulence at the South Pole and its implications for astronomy, Astron. Astrophys., 400, 1163-1172.

Turner, J., T. A. Lachlan-Cope, S. R. Colwell, G. J. Marshall, and W. M. Connolley (2006), Significant warming of the Antarctic winter troposphere, Science, 311, 1914-1917.

Vaisala (2005), RS92 manufacturer's brochure, Tech. Rep. B210358EN-C, Vantaa, Finland

van As, D., and M. van den Broeke (2006), Structure and dynamics of the summertime atmospheric boundary layer over the Antarctic Plateau: 2. Heat, moisture, and momentum budgets, J. Geophys. Res., 111, D07103, doi:10.1029/2005JD006956.

van As, D., M. van den Broeke, and R. van de Wal (2005), Daily cycle of the surface layer and energy balance on the high Antarctic Plateau, Antarct. Sci., 17, 121-133.

Walden, V. P., M. S. Town, B. Halter, and J. Storey (2005), First measurements of the infrared sky brightness at Dome C, Antarctica, Publ. Astron. Soc. Pac., 117(829), 300-308.

Wang, J., H. L. Cole, D. J. Carlson, E. R. Miller, K. Beierle, A. Paukkunen, and T. K. Laine (2002), Corrections of humidity measurement errors from the Vaisala RS80 radiosonde: Application to TOGA COARE data, J. Atmos. Oceanic Technol., 19, 981-1002.

S. Argentini, Istituto di Scienze dell'Atmosfera e del Clima, CNR, Area di Ricerca di Roma Tor Vergata, Via del Fosso del Cavaliere, 100, I-00133 Rome, Italy.

V. Favier, C. Genthon, D. Six, and M. S. Town, Laboratoire de Glaciologie et Geophysique de l'Environnement, UMR 5183, 54 rue Moliere BP96, F-38402 Saint Martin d'Heres CEDEX, France. (genthon@ lgge.obs.ujf-grenoble.fr)

A. Pellegrini, Programma Nazionale Ricerche in Antartide, ENEA, Via Anguillarese 301, S. Maria di Galeria, I-00123 Rome, Italy. 